\title{
Effects of Oestrogen on MicroRNA Expression in Hormone-Responsive Breast Cancer Cells
}

\author{
Lorenzo Ferraro • Maria Ravo • Giovanni Nassa • \\ Roberta Tarallo • Maria Rosaria De Filippo • \\ Giorgio Giurato • Francesca Cirillo • Claudia Stellato • \\ Silvana Silvestro $\cdot$ Concita Cantarella $\cdot$ \\ Francesca Rizzo • Daniela Cimino • Olivier Friard • \\ Nicoletta Biglia • Michele De Bortoli • Luigi Cicatiello • \\ Ernesto Nola $\cdot$ Alessandro Weisz
}

Published online: 25 January 2012

(C) Springer Science+Business Media, LLC 2012 genes. Here, we analysed changes in miRNA expression in response to oestrogen in hormone-responsive breast cancer MCF-7 and ZR-75.1 cells by microarray-mediated expression profiling. This led to the identification of 172 miRNAs up- or down-regulated by ER $\alpha$ in response to $17 \beta$ oestradiol, of which 52 are similarly regulated by the hormone in the two cell models investigated. To identify mechanisms by which ER $\alpha$ exerts its effects on oestrogenresponsive miRNA genes, the oestrogen-dependent miRNA

Electronic supplementary material The online version of this article (doi:10.1007/s12672-012-0102-1) contains supplementary material, which is available to authorized users.

L. Ferraro $\cdot$ M. Ravo $\cdot$ G. Nassa $\cdot$ R. Tarallo $\cdot$ G. Giurato $\cdot$ C. Stellato $\cdot$ S. Silvestro $\cdot$ C. Cantarella $\cdot$ F. Rizzo $\cdot$ A. Weisz $(\square)$ Laboratory of Molecular Medicine and Genomics, Faculty of Medicine and Surgery, University of Salerno,

via S. Allende 1,

84081 Baronissi, Salerno, Italy

e-mail: aweisz@unisa.it

L. Ferraro $\cdot$ F. Cirillo $\cdot$ L. Cicatiello $\cdot$ E. Nola $\cdot$ A. Weisz

Department of General Pathology, Second University of Naples, vico L. De Crecchio 7,

80138 Napoli, Italy

\section{R. De Filippo}

Fondazione IRCCS SDN,

via Gianturco 113,

80143 Naples, Italy

D. Cimino

Molecular Biotechnology Center and Department of Oncological Sciences, University of Turin,

via Nizza 52 ,

10126 Turin, Italy

O. Friard $\cdot$ M. De Bortoli

Center for Molecular Systems Biology, University of Turin, via Accademia Albertina 13,

10123 Turin, Italy

N. Biglia

Department of Obstetrics and Gynecology, Mauriziano 'Umberto

I' Hospital, University of Turin,

Largo Turati 62,

10128 Turin, Italy

A. Weisz

Division of Molecular Pathology and Medical Genomics, 'SS.

Giovanni di Dio e Ruggi d'Aragona' Hospital,

University of Salerno,

via San Leonardo,

84131 Salerno, Italy 
expression profiles were integrated with global in vivo ER $\alpha$ binding site mapping in the genome by ChIP-Seq. In addition, data from miRNA and messenger RNA (mRNA) expression profiles obtained under identical experimental conditions were compared to identify relevant miRNA target transcripts. Results show that miRNAs modulated by $\mathrm{ER} \alpha$ represent a novel genomic pathway to impact oestrogen-dependent processes that affect hormoneresponsive breast cancer cell behaviour. MiRNome analysis in tumour tissues from breast cancer patients confirmed a strong association between expression of these small RNAs and clinical outcome of the disease, although this appears to involve only marginally the oestrogen-regulated miRNAs identified in this study.

Keywords Oestrogen receptor - Breast cancer - MicroRNA . Cell cycle $\cdot$ Gene expression

\section{Introduction}

The steroid hormone $17 \beta$-oestradiol (E2) is a key regulator of growth and differentiation in the mammary gland $[1,2]$ where it is involved in the pathogenesis and clinical outcome of breast cancer (BC) [3]. In normal and transformed mammary epithelial cells, the biological effects of E2 are mediated primarily by oestrogen receptor alpha $(E R \alpha)$, a ligand-inducible transcription factor of the nuclear receptor gene superfamily. Following oestrogenic activation, ER $\alpha$ mediates transcription by interacting directly with specific oestrogen response elements (EREs) located in the promoter/enhancer region of its target genes; it can also interact with other transcription factor complexes like Fos/Jun [4] or SP-1 [5] influencing transcription of genes whose promoters do not harbour ERE (tethering). This leads to transcriptional activation or repression of target genes involved in important cellular function such as cell cycle control, differentiation and apoptosis [6-8]. Alternatively, oestrogens are able to trigger rapid and transient cellular responses via ER $\alpha$ crosstalk with different signal transduction pathways in the cytoplasm $[9,10]$. The cellular response to oestrogens involves multiple biological events, including transcription, RNA stability and post-translational modifications [11]. MicroRNAs (miRNAs) are a class of small RNAs of 23 nucleotides (nt) in length, which coordinate a broad range of gene expression programs mainly through modulation of gene regulation [12]. There are over 1,700 identified miRNAs in the human genome that are, themselves, subject to regulation at both transcriptional and post-transcriptional level. MiRNAs are encoded in several regions of the genome, both in protein coding and non-coding transcription units. Approximately $50 \%$ of miRNAs are derived from non-coding RNA transcripts and have their own promoters, while an additional $40 \%$ are located within the introns of protein coding genes and share the same transcriptional control of the host genes [13, 14]. Moreover, many miRNAs are encoded in the genome as clusters that can range from 2 to 19 miRNA hairpins, encoded in tandem and in close proximity to each other [15]. After being transcribed, miRNA carrier transcripts (pri-miRNA [16]) undergo a step-wise processing: The long miRNA transcript is cleaved into the nucleus by Drosha into pre-miRNA [17], exported into the cytoplasm and there cleaved by Dicer into a miRNA-miRNA* duplex [18]; mature miRNAs are loaded into microRNA-induced silencing complex (miRISC), which interferes with the transfer of transcriptome information into proteome output via RNA-induced gene silencing [19-21]. Regardless of the mechanisms, each miRNA can potentially regulate gene expression of hundreds of genes, and on the other hand, a single transcript can be targeted by multiple miRNAs $[22,23]$. In fact, almost one third of the protein-coding genes are under the regulation of miRNAs, and, as a consequence, many miRNAs seem to play a crucial role in different biological processes such as differentiation, proliferation and cell death in a context-dependent way [24]. Not surprisingly, aberrant miRNA expression is a hallmark of several diseases, including cancer [25]. Several studies have established a role of miRNAs in the pathogenesis of $\mathrm{BC}$, showing a link between E2/ERs and microRNAs expression either in $\mathrm{BC}$ cell lines or in cancerous breast tissues [26-30]. These studies indicate that miRNAs can act as either oncogenes or oncosuppressors [31]. In addition, identification of differential expression profiles of miRNAs between normal and neoplastic breast tissue or among human $\mathrm{BC}$ subgroups confirms the hypothesis of a possible involvement of miRNAs in tumour development and progression [32-35]. The expression of miRNAs has been examined in different $\mathrm{BC}$ cell lines and biopsies. Among these, the most consistently deregulated miRNAs following E2 treatment were miR-206, miR-125a/b, miR-17-5p, miR$34 \mathrm{a}$ and some member of let-7 family that may act as tumour suppressor genes [36]. Some recent reports, in fact, have shown that E2 treatment leads to alteration of miR-206 whose expression levels decrease in ER $\alpha$-positive human BC tissues. This miRNA is able to suppress ESR1 expression and to inhibit growth of MCF-7 BC cells [37]. Moreover, miR-17-5p represses the translation of AIB1 mRNA, thereby inhibiting the function of E2F1 and ER $\alpha$. Downregulation of AIB1 by miR-17-5p results in the suppression of oestrogen-stimulated proliferation and oestrogen/ER-independent BC cell proliferation [38, 39]. MiRNA let-7, one of the first discovered members of let-7 family, is poorly expressed or deleted in many human cancers as well as miR34a, which has been shown to be transcriptionally regulated also by $\mathrm{p} 53$ [40]. On the other hand, miR-21, miR-155 and miR-10b may act as oncogenes, being consistently found 
over-expressed in cancer. Consistent with these findings, miR-21 was also shown to be highly up-regulated in breast tumours compared to the normal breast tissues, suggesting its oncogenic role [41]. Moreover, miR-21 together with let7 and miR-98 are involved in a negative-regulatory loop that controls c-Myc, E2F1 and E2F2 protein levels [28].

A number of genes involved in $\mathrm{BC}$ progression have been identified by in silico analyses and then experimentally proven to be targets of miRNAs that are deregulated in breast tumours [42]. Furthermore, it has been shown that miRNA deregulation in $\mathrm{BC}$ can occur not only at the transcriptional level but also at the processing level. In fact, it was recently reported that E2 is able to up-regulate Dicer1 gene expression in ER $\alpha$-positive BC cells [28]. Furthermore, some miRNAs, including miR-221/222 and miR29a (highly expressed in ER $\alpha$ negative BC cells), directly repress ER $\alpha$ and Dicer1 expression; in contrast, miR-200c (highly expressed in $\mathrm{ER} \alpha$-positive $\mathrm{BC}$ cells) increases Dicer1 levels [43].

In this study, we performed a time-course analysis of oestrogen-regulated miRNAs in MCF-7 and ZR-75.1 cell lines, with the aim to identify all miRNAs showing identical kinetics and type of response to the hormone in this $\mathrm{BC}$ cell model. In order to identify relevant miRNA target transcripts, we then performed a functional analysis of the E2regulated miRNAs by integrating data from both miRNA and mRNA expression profiles obtained under identical experimental conditions. To determine the mechanisms by which ER $\alpha$ exerts its effects on target miRNAs, data derived from global analyses of ER $\alpha$ in vivo binding sites to the genome upon E2 stimulation in MCF-7 cells were integrated with hormone-responsive miRNome data. Finally, to investigate the role of miRNA expression in primary breast tumours, we analysed in silico miRNomes from tumour specimens from patients with divergent clinical outcomes following surgical treatment to evaluate existing correlations between the expression patterns of oestrogenresponsive miRNAs identified in cellular models of the disease and clinical-pathological parameters of $\mathrm{BC}$.

\section{Materials and Methods}

\section{Cell Culture and Imunoblotting}

Human hormone-responsive BC cells MCF-7 Tet-Off (Clontech-Takara, Saint-Germain-en-Laye, France) and ZR-75.1 (ATCC CRL-1500) were grown in Dulbecco's modified Eagle's medium (Sigma-Aldrich, Milan, Italy) supplemented with $10 \%$ foetal bovine serum (HyClone, Cramlington, UK) and antibiotics: $100 \mathrm{U} / \mathrm{ml}$ penicillin, $100 \mathrm{mg} / \mathrm{ml}$ streptomycin, $250 \mathrm{ng} / \mathrm{ml}$ Amfotericin-B and $50 \mu \mathrm{g} / \mathrm{ml} \mathrm{G} 418$. Cells were routinely tested for mycoplasma infection using MycoAlert mycoplasma detection kit (Cambrex BioScience, Rockland, ME, USA). For G0-G1 synchronisation, cells were plated at $20-40 \%$ confluence in steroid-free medium (phenol red-free Dulbecco's modified Eagle's medium with $5 \%$ foetal bovine serum, pre-treated with dextran-coated charcoal and antibiotics) and maintained for 4 days with replacement of the same fresh medium before stimulation with $10^{-8} \mathrm{M} 17 \beta$-estradiol (+E2) or EtOH (vehicle) as negative control. ER expression in cell lines was assayed by sodium dodecyl sulphate (SDS) polyacrylamide gel electrophoresis and immunoblotting of total protein extracts, using rabbit polyclonal anti-ER $\alpha$ (sc-543, Santa Cruz Biotechnology, Heidelberg, Germany) as previously described [44].

\section{Patients}

Thirty-two frozen tumour specimens were selected from a former cohort [45]. They were obtained from patients who underwent primary surgical treatment between 1988 and 2001 at a median age of 57 (range, 32-79). Twenty-two cases were oestrogen receptor (ER) positive and treated in the adjuvant setting with $20 \mathrm{mg}$ tamoxifen daily for 5 years alone or in combination, while 10 cases were ER negative. The average follow-up was of 89 months. ER and PgR status was determined by immuno-histochemical stainings; samples were defined positives when tumours contained more than $10 \%$ positive cells. Details are provided as Supplementary Table S3.

\section{RNA Purification}

Total RNA was extracted from control (+EtOH, -E2) and from hormone-stimulated (+E2) cell cultures with Trizol (Invitrogen, Carlsbad, CA, USA), as described previously [46]. In each case, cells were collected from multiple parallel cultures and pooled before RNA extraction as described before [47]. For tumour samples, after surgical removal, total RNA was isolated with Concert Cytoplasmic RNA Reagent (Invitrogen Life Technologies, Carlsbad, CA, USA) from 20 to $50 \mathrm{mg}$ tumour tissues, according to the manufacturer's guidelines. Frozen tumours were placed in this reagent and homogenised using a ball mill (MM200, Retsch, Düsseldorf, Germany). The suspension was centrifuged at $14,000 \times \mathrm{g}$ for $5 \mathrm{~min}$ at $4^{\circ} \mathrm{C}$, then lysed with $0.1 \mathrm{ml}$ of $10 \%$ SDS followed by $0.3 \mathrm{ml}$ of $5 \mathrm{M}$ sodium chloride and $0.2 \mathrm{ml}$ of chloroform for milliliters of reagent. The lysate was centrifuged at $14,000 \times \mathrm{g}$ for $15 \mathrm{~min}$ at $4^{\circ} \mathrm{C}$, and the upper aqueous phase was removed and combined with 0.8 volume of isopropyl alcohol for $10 \mathrm{~min}$ at room temperature. The RNA was recovered by centrifugation, washed with 75\% ethanol and finally dissolved in RNase-free water. Before use, RNA concentration in each sample was 
determined with a ND-1000 spectrophotometer (NanoDrop, Wilmington, DE, USA) and quality assessed with Agilent 2100 Bioanalyser (Agilent Technologies, Santa Clara, CA, USA).

\section{Microarray Analyses}

For miRNA expression profiling, technical replicates were produced. For MCF-7 cells, 800 ng of total RNA were fluorescently labelled and amplified in triplicate to be then pooled for the hybridisation; for ZR-75.1 cells and breast tumour samples, the same concentration of RNA were fluorescently labelled, amplified and hybridised at least in duplicate. Hybridisation reactions were performed with Illumina v2 MicroRNA Expression BeadChips, according to the protocols provided by the array manufacturer (Illumina Inc., San Diego, CA, USA). The human microRNA panel used comprises 1,145 probes designed on miRNA sequence present in miRBase database (Release 12.0) and on additional novel content derived using Illumina sequencing technology. For mRNA expression profiling, $500 \mathrm{ng}$ total RNA from MCF-7 and ZR-75.1 were reverse transcribed, as described previously [48, 49], used for synthesis of complementary DNA and biotinylated complementary RNA (cRNA), according to the Illumina TotalPrep RNA amplification kit (Ambion, Austin, TX, USA; category number IL1791) protocol. For each sample, $700 \mathrm{ng}$ of cRNA were hybridised for $18 \mathrm{~h}$ at $55^{\circ} \mathrm{C}$ on Illumina HumanWG-6 version 2.0 BeadChips containing 48701 probes (Illumina Inc., San Diego, CA, USA), according to the manufacturer's protocol. The BeadChips were scanned using Illumina BeadArray Reader 500 according to the manufacturer's standard methods.

\section{MicroRNA Expression Profiling Data Analysis}

For data analysis, the fluorescence intensity files were loaded into the Illumina GenomeStudio v2009.1 software for quality control and expression analysis. First, the quantile normalisation algorithm was applied on the raw datasets to correct systematic errors. This normalisation equalises distribution, median and mean of probe intensities among all samples, as the normalised distribution is chosen by averaging each quantile across samples. For differential expression analysis, technical replicates were grouped together, and miRNAs with a detection $p<0.01$, corresponding to a false positive rate of $1 \%$, were considered as expressed. Statistical significance was calculated with the Illumina DiffScore, a proprietary algorithm that uses the bead standard deviation to build an error model. Only miRNAs with a DiffScore $\leq-20$ and $\geq 20$, corresponding to a $p=0.01$, were considered as statistical significant. The microarray data were deposited in the Array Express repository database with the following accession numbers: E-TABM-1194.

\section{Breast Tumour Data Analysis}

Raw data were normalised as described above using GenomeStudio v. 2009.1, and only probes with $p<0.05$ were selected for further analysis. A total of 1,021 probes had at least one valid call in a tumour sample. Two tumour samples had $<10$ valid data and were not included. Furthermore, to avoid unbalancing, only probes showing valid calls in at least 20 tumour samples were used in clustering and differential expression analysis (739 probes). Data were normalised to the median value in all tumour samples $(N=30)$ and converted to $\log (\log$ ratio). Unsupervised hierarchical clustering was performed using TMev package (MultiExperiment Viewer, at www.t4m.org/mev) using the HCL with Pearson's correlation with complete or average linkage, depending on sample/gene number. Differential expression analysis was carried out using the SAM routine in the same package, using 5,000 permutations and Tusher's S0 [50]. Clusters defined by the HLC were then compared in terms of overall survival (OS) or disease-free survival (DFS) using Kaplan-Meier log rank correlation. Survival curves were generated with PASW 18.0 statistical software.

\section{Quantitative Real-time RT-PCR}

Total RNA was extracted from MCF-7 cells before and after stimulation for $72 \mathrm{~h}$ with $10^{-8} \mathrm{M}$ E2 as described above. Mature miRNAs were reverse transcribed using a miRNAspecific stem loops and reverse transcriptase before real-time PCR performed using Taqman microRNA assays (assay ID: 2439, 2445, 2441, 2126, 2174, 2440, 2333; Applied Biosystems), as described by Grober et al. [51]. RNU49, unaffected by hormone treatment (data not shown), was used as an internal control to normalise all data using the Taqman RNU49 assay (Applied Biosystems). All real-time PCR runs were performed on a MJ Research PTC-200 Opticon Instrument.

\section{ChIP-Seq Data Analysis}

For determining the ER $\alpha$ genome-wide binding sites, we have re-analysed the ChIP-Seq data (accession number EMTAB-131) previously published by Cicatiello et al. [48]. Enriched regions from MCF-7 cells stimulated with $17 \beta-$ estradiol for $45 \mathrm{~min}(+\mathrm{E} 2)$ were compared with the same from MCF-7 cultured maintained in steroid-free medium (-E2), with FindPeaks [52], setting the value of subpeaks parameter to 0.5 . For selecting only the most relevant sites, we have applied the first quartile as statistical cut-off. For evaluating the nearest ER $\alpha$ binding sites to the miRNA genes within $50 \mathrm{~kb}$, we have used windowBed of the suite programs BEDTools [53]. 
MicroRNA Target Prediction and Functional Analysis of Their Predicted MRNA Targets

For comprehensive prediction of miRNA target genes we used TargetScan, release 5.1 (www.targetscan.org). To identify statistically over-represented 'biological process' Gene Ontology terms among sets of selected mRNA targets, we used the Database for Annotation, Visualization and Integrated Discovery (DAVID, http://david.abcc.ncifcrf.gov) functional annotation tool $[54,55]$. To this aim we used as background data coming from gene expression profiling experiments previously performed [48] on the same cell lines and under the same experimental conditions investigated in this study.

\section{MiRNA Localisation in Host Genes}

We annotated the genomic position and context of microRNAs in human genome. This analysis was performed with RegionMiner [56] application of the Genomatix software suite, which generates statistic annotation and data for chromosomal regions.

\section{Results}

Characterisation of ER $\alpha$ Positive Breast Cancer Cell Lines

The two ER $\alpha$-positive breast carcinoma cell lines MCF-7 and ZR-75.1 were used as in vitro model of hormoneresponsive $\mathrm{BC}$; $\mathrm{ER} \alpha$ expression was monitored by Western blot analysis, using as control extracts from ER $\alpha$ negative SKBR3 cells (Fig. 1a). In these cell lines, E2 deprivation induces G1 arrest [57], a quiescence status readily overrun by administration of physiological concentrations of E2. This determines resumption of cell cycle progression, mediated by regulation of cell cycle control pathways [58]. Indeed, analysis of hormone-deprived MCF-7 and ZR-75.1 cell cultures before and after oestrogen $\left(\mathrm{E} 210^{-8} \mathrm{M}\right)$ stimulation show the timed accumulation of cyclins that characterise cell cycle progression (Fig. 1b). In MCF-7 cells (upper panel), oestrogen-induced accumulation of the G1 cyclin D1 is detectable already after $4 \mathrm{~h}$ of stimulation, remaining high throughout the pre-replicative phase, and to a lower extent also during the $\mathrm{S}$ phase. Cyclin E2 concentration is also affected by hormone stimulation, showing a 1.5- to 2-fold induction after $10 \mathrm{~h}$ and lasting for up to $24 \mathrm{~h}$. The cellular levels of the S-G2 phase cyclins A2 and B1 progressively accumulate in a latter time. The results were also confirmed in ZR-75.1 cells (lower panel of Fig. 1b), which show a good degree of oestrogen dependence and a similar pattern of cyclin gene activation occurring, however, faster than in MCF-7 cells. These molecular responses to E2, occurring in both cell lines, confirm the direct stimulatory action of oestrogen under the conditions used for this study.

Identification of Oestrogen-Regulated MiRNAs

In order to study the effects of the oestrogen on miRNAs expression, we performed a time-course analysis following oestrogen in both $\mathrm{BC}$ cell lines selected for this study. To this aim, total RNA was extracted from MCF-7 and ZR-75.1 cells before and after different time points of stimulation

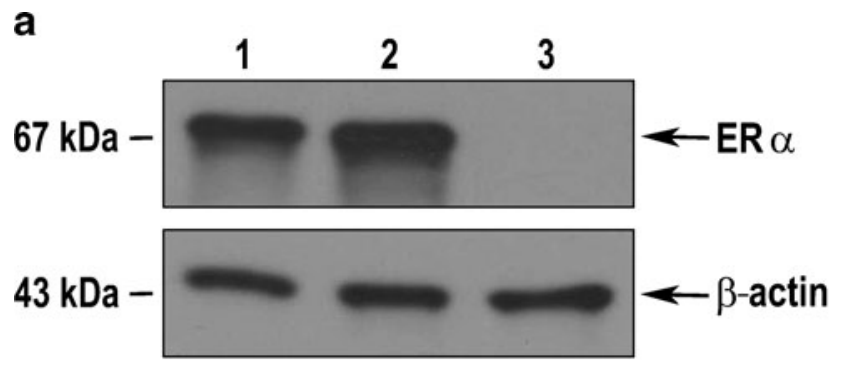

b - cyclin D1 - cyclin E2 $\Delta$ cyclin A2 • cyclin B1

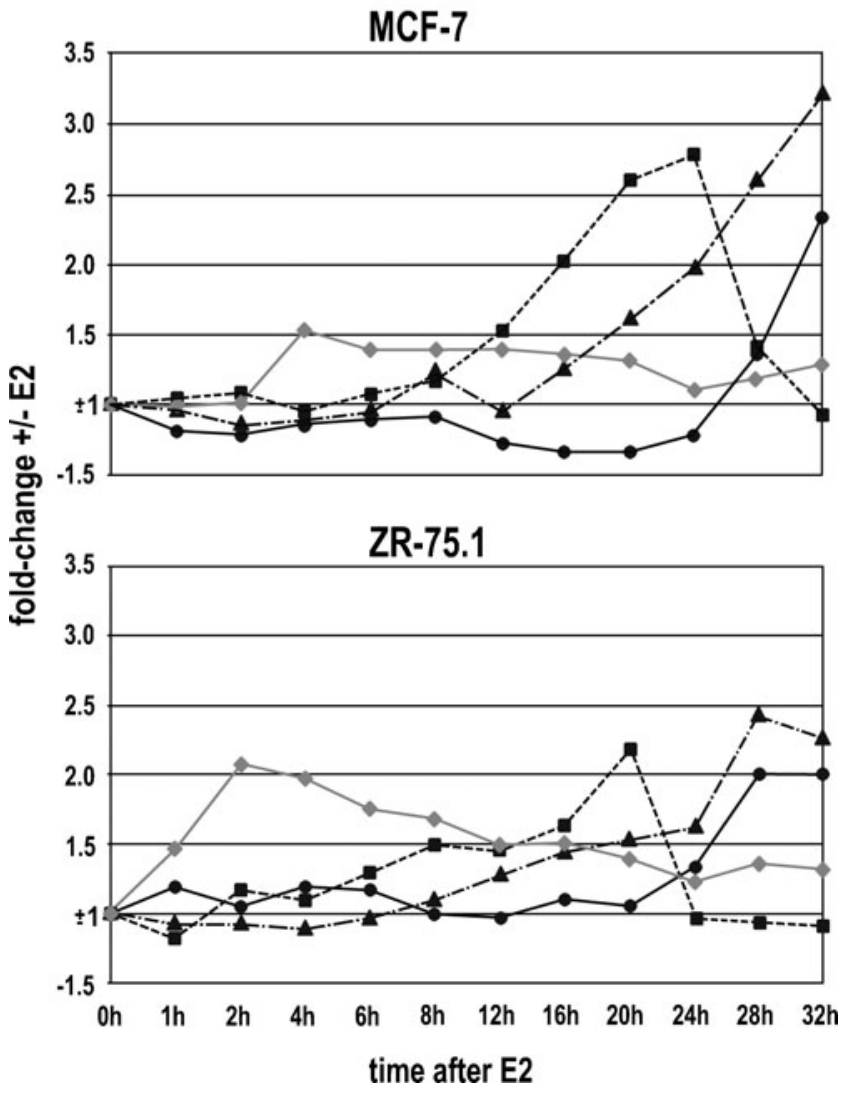

Fig. 1 Characterization of ER $\alpha$-positive breast cancer cell lines. a Expression level of ER $\alpha$ by Western blot analysis of protein extracts from MCF-7 (lane 1), ZR-75.1 (lane 2) and SKBR3 (lane 3) cells. b Monitoring of cyclin gene expression in G1-synchronised MCF-7 and ZR-75.1 cell lines following stimulation with a mitogenic dose of E2 
with a mitogenic dose of E2 $(6,12,24$ and $72 \mathrm{~h})$, and a global analysis of miRNA expression profiles was carried out by microarray hybridisation as described in 'Materials and Methods', using a platform (Illumina MicroRNA Expression Beadchip) detecting most known and characterised miRNAs. Results indicate that, in agreement with what previously reported in this cell type $[28,30,43,48,59$, $60]$, this hormone can indeed affect significantly the intracellular concentration of specific miRNAs. Among all known miRNAs, we identified 230 showing significant changes in expression in response to E2 $(p \leq 0.01)$, including 110 that changed in both cell lines ( 52 responding similarly and 58 showing opposite changes), 51 restricted to MCF-7 cells and 69 restricted to ZR-75.1 cells. The 52 miRNAs showing concordant regulation in the two cell lines, 25 down- and 27 up-regulated (Fig. 2 central panel), were considered good candidates to investigate miRNA involvement in oestrogen signalling and for this reason selected for further analysis. In Fig. 3 are displayed in graphic format the actual values of the fluctuations detected for 14 miRNAs showing representative expression profiles. Reliability of the microarray platform used for this study was throughly controlled in our laboratory in a previous study [30]; however, a test was performed by real-time RT-PCR on seven miRNAs in MCF-7 cells $72 \mathrm{~h}$ after hormone (Supplementary Fig. S1). The results confirm a good correlation between Q-PCR and microarray measurements.

Putative Targets of E2-Regulated miRNAs and Functional Analysis of their Predicted Targets

In order to evaluate the functional roles of the 52 miRNAs responsive to E2 treatment in both MCF-7 and ZR-75.1 cells, we performed an in silico functional analysis exploiting previously described mRNA expression profiling data obtained in the same cell lines under comparable experimental conditions [48]. To this aim, we first searched for mRNAs putative targets of these oestrogen-regulated miRNAs, results show that $\sim 30 \%$ of all expressed mRNAs indeed represent potential targets of these small RNAs [48], and the same is true for $33 \%$ mRNAs found regulated by oestrogen in the same study. In order to identify biological processes likely to be influenced by ER $\alpha$ via miRNAs in our cell lines, a Gene Ontology analysis was performed by DAVID tool, using as background the list of expressed mRNAs identified previously [48]. The results reported in Supplementary Fig. S2 show how several cellular processes were found statistically enriched by ER $\alpha$-responsive miRNAs, including those known to be affected by ER $\alpha$, such as response to hormonal stimuli, regulation of transcription and cell proliferation, and other that represent key cellular processes in tumour cells, such as cell migration, adhesion and differentiation. Furthermore, starting from the assumption that miRNA up-regulation might result in down-regulation of its mRNA targets, and vice versa, we investigated the existence of dynamic inverse relationships between miRNA and mRNA levels in oestrogen-stimulated cells. To evaluate this possibility, we first searched for the presence of perfect or imperfect matches between the seed sequence of each regulated miRNA and the untranslated region (UTR) of their putative mRNA targets. Interestingly, we could find only perfect complementarity between these two sequences, a finding that strongly supports the possibility of the existence of a pathway controlling mature mRNA half-life in hormone-responsive BC cells, whereby E2-activated ER $\alpha$ exerts a post-transcriptional control on its target gene activity via specific miRNAs. Indeed, when considering all mRNAs targeted by a single miRNA, we observed a clear inverse relationship between changes in miRNA concentration and that of the corresponding target mRNAs in about $50 \%$ of the cases 125 mRNAs of the 252 identified putative targets (listed in Supplementary Table S1).

\section{E2-Regulated miRNAs Associated with ER $\alpha$-Binding Sites or Located in the Intragenic Region of Oestrogen-Responsive Genes}

Current understanding of microRNA biogenesis indicates that expression of these small RNAs can be modulated either during their transcription or through the multiple steps leading to their maturation. In order to identify the transcriptional mechanisms by which activated ER $\alpha$ exerts its effects on oestrogen-responsive miRNAs, we integrated two global genomic analyses of ER $\alpha$ in vivo binding sites $[48,61]$ with the miRNome expression profile obtained in this study. In this way, we could observe that some E2-responsive miRNAs indeed display ER $\alpha$ binding sites within $10 \mathrm{~kb}$ of the transcription unit (Table 1). In particular, six of these miRNA genes are associated with one or more ER $\alpha$ binding sites, suggesting a mechanism for direct regulation of RNA biogenesis exerted also in this case by chromatin-bound ER. However, recent findings suggest that the receptor is able to perform its action even when its binding site is not in close proximity of the regulated genes. In order to evaluate this possibility, we expanded our search to $50 \mathrm{~kb}$ around miRNA genes, leading to the identification of 18 more miRNA genes linked to one or more ER $\alpha$-binding sites (Supplementary Table S2). As approximately $50 \%$ of miRNAs are transcribed from introns of protein-coding genes, while the others are intergenic [62], we searched for E-regulated protein-coding genes harbouring miRNA genes and aligned the results with those relative to E2-regulated miRNAs. The results are reported in Table 2 to show that six E2-regulated miRNAs are located within oestrogen-dependent genes. Interestingly, in most cases, the miRNA follows the same regulation trend of the harbouring gene. 
a

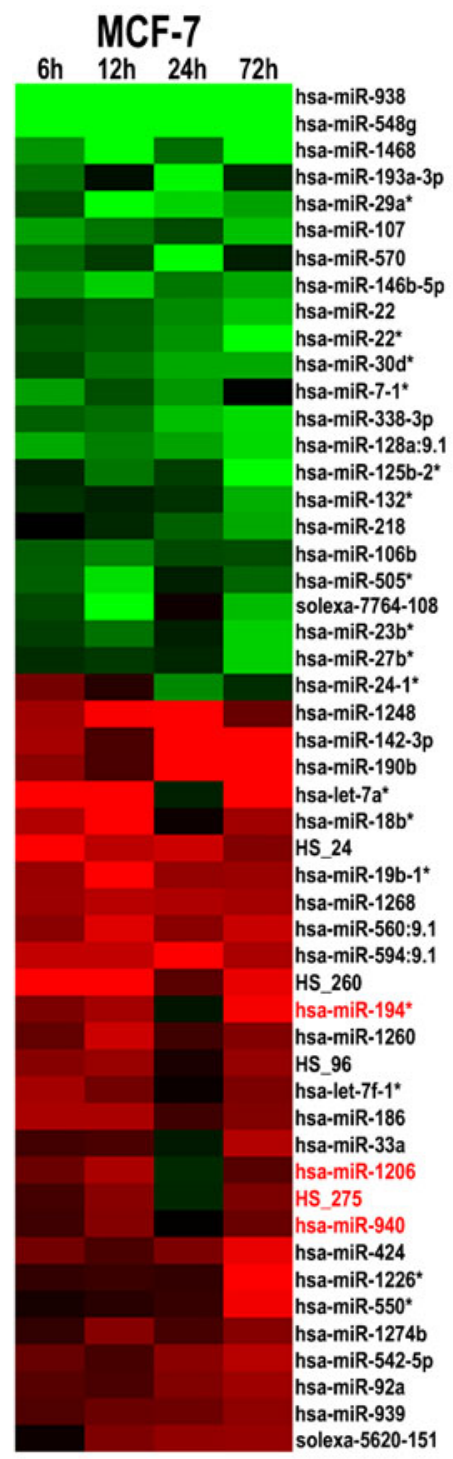

b

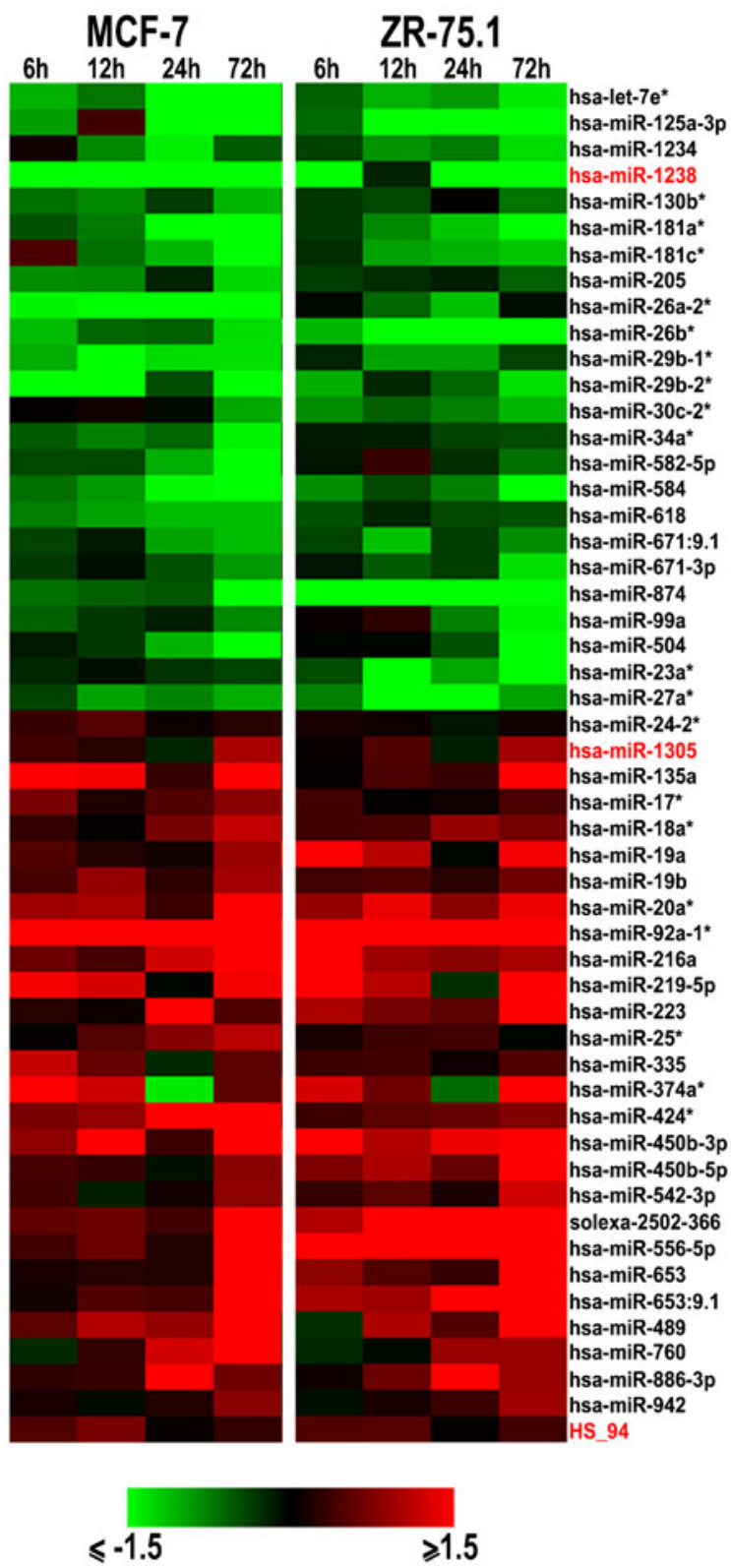

C

ZR-75.1

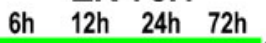

hsa-miR-379 hsa-miR-646 hsa-miR-632 HS 166.1 hsa-miR-376a hsa-miR-221* hsa-miR-582-3p hsa-miR-1303 hsa-miR-487b hsa-miR-708* hsa-miR-377 hsa-miR-185* HS_196.1 hsa-miR-610 hsa-miR-99b* hsa-miR-204 HS_209.1 solexa-1460-671 hsa-miR-1229 HS_108.1 hsa-miR-935 hsa-miR-589 hsa-miR-589
hsa-let-7i* hsa-let-7i* hsa-miR-345 hsa-miR-194* hsa-miR-1225-3p hsa-miR-21* hsa-miR-196b hsa-miR-330-5p hsa-miR-328 hsa-miR-1301 hsa-miR-375 hsa-miR-375
hsa-miR-199a/b-3p HS_99.1 hsa-miR-663b hsa-miR-122 hsa-miR-491-3p hsa-miR-548d-3p solexa-5169-164 hsa-miR-660 hsa-miR-660 hsa-miR-643 hsa-miR-210 hsa-miR-199a*:9.1 HS 29 hsa-miR-16-1* hsa-miR-16-1 hsa-miR-363 hsa-miR-449a hsa-miR-708
hsa-miR-652 hsa-miR-455-3p hsa-miR-1323 hsa-miR-1826 hsa-miR-628-5p hsa-miR-651 hsa-miR-18a hsa-miR-18a hsa-miR-499-5p hsa-miR-590-3p hsa-miR-548e hsa-miR-135b hsa-miR-190 hsa-miR-579 hsa-miR-455-5p solexa-539-2056 HS 78 HS_78 hsa-miR-376b
hsa-miR-195*

Fig. 2 Effects of $E R \alpha$ on miRNome of human breast cancer cell lines. Time-course analysis of miRNA expression profiles in MCF-7 and ZR75.1 cell lines after cells exposure to E2 for the indicated times. Oestrogen-regulated miRNAs are grouped as follows: regulated in MCF-7 cells only (a), in both cell lines (b) or in ZR-75.1 cells only (c). Data displayed

Regulation of miRNA Expression in Breast Tumour Samples

We next evaluated expression of the hormone-regulated miRNAs identified here in primary BC tissue samples. For this, we performed miRNA expression profiling in represent the ratio between the fluorescence intensity values of each miRNA at the indicated time after exposure to $10^{-8} \mathrm{M}$ E2 vs the corresponding $0 \mathrm{~h}$ time point. MicroRNAs marked in red represent those regulated in $\mathrm{BC}$ cell lines in vitro and those displaying differential expression between primary breast tumour subgroups (see Fig. 4) breast tumour samples as described in 'Materials and Methods'. All miRNA probes that showed valid calls in at least 20 tumour samples were used in the statistical analysis for correlation with clinic-pathological parameters. Of these 739 probes, 161 were regulated by oestrogen in at least one cell line, whereas 49 were 


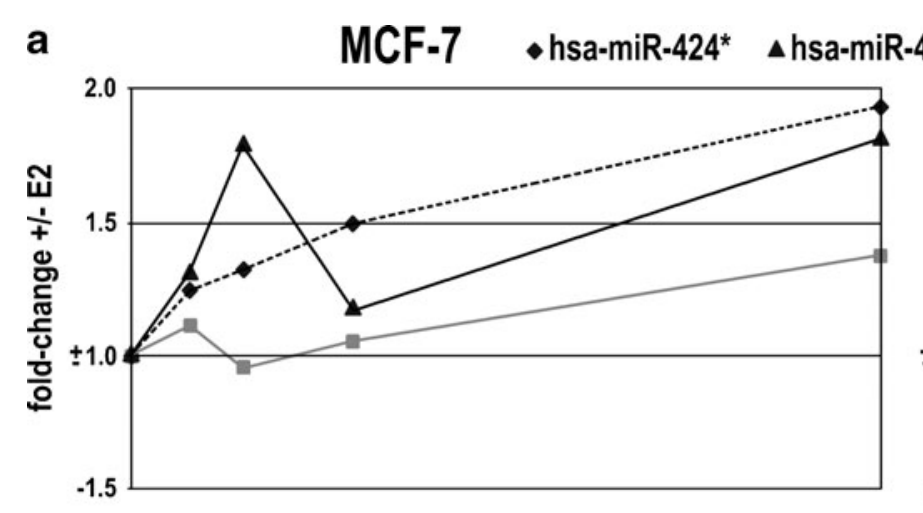

\section{-450b-3p = hsa-miR-542-3p ZR-75.1}

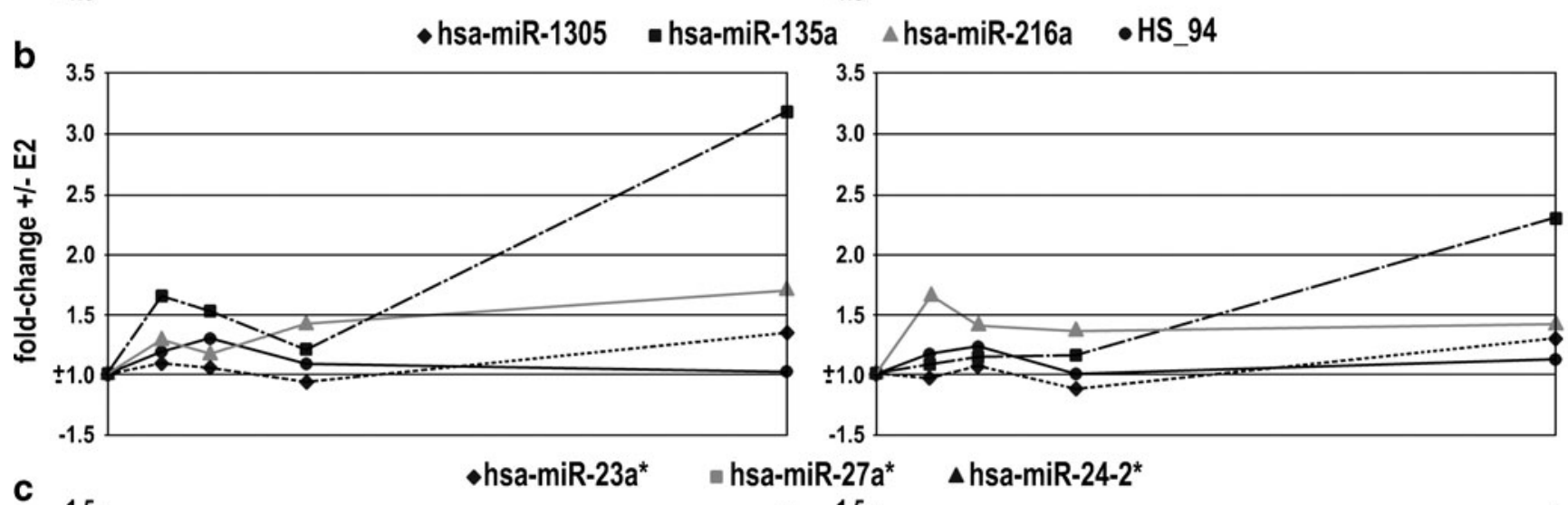

C

•hsa-miR-23a* = hsa-miR-27a* $\Delta$ hsa-miR-24-2*
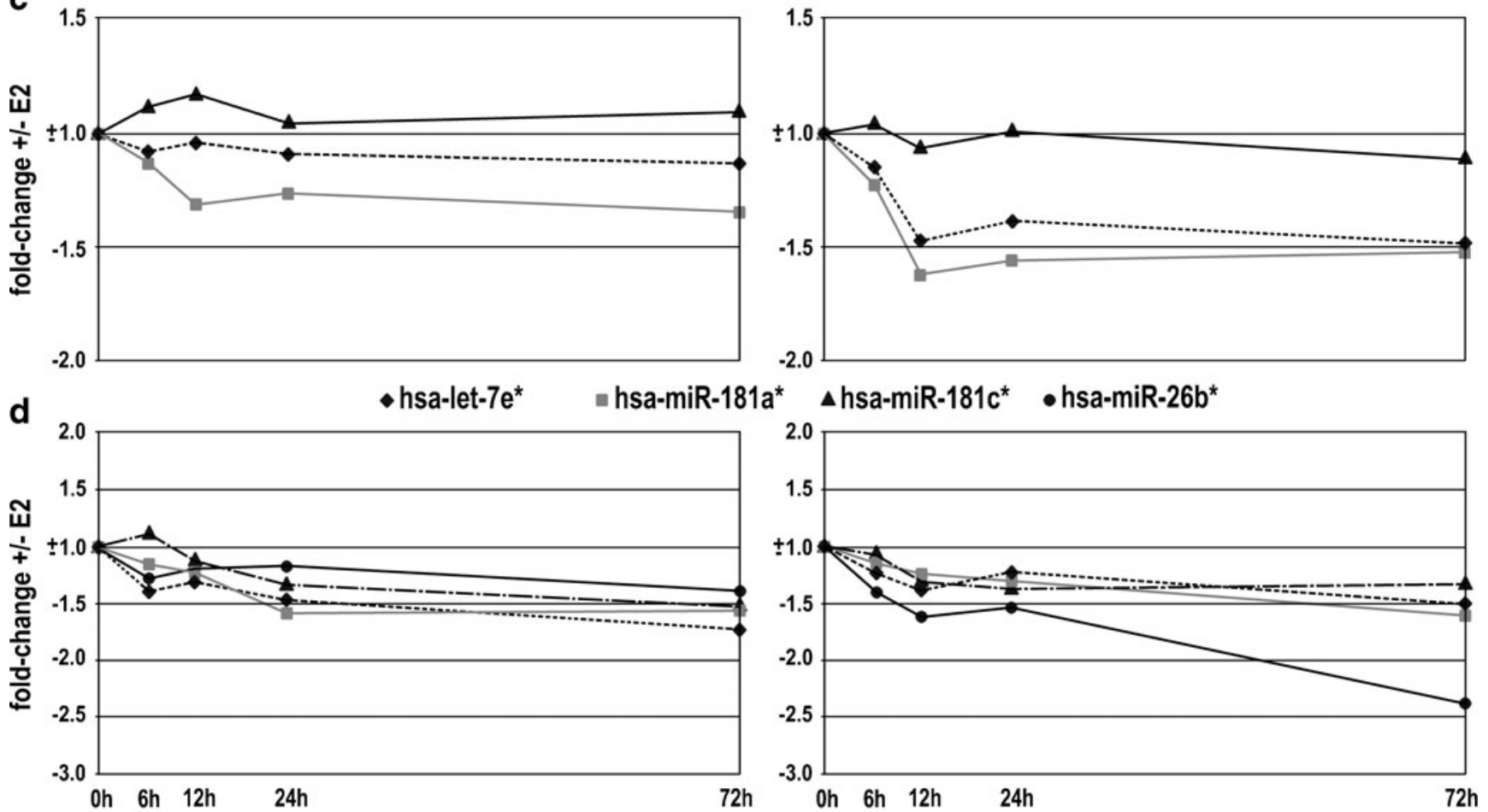

time after E2

Fig. 3 Graphic representation of timed fold-change variations of selected E2-regulated miRNAs in MCF-7 and ZR-75.1 cell lines. MicroRNAs shown are members of clusters $(\mathbf{a}, \mathbf{c})$ or are encoded as independent transcript $(\mathbf{b}, \mathbf{d})$

regulated in both cell lines examined. First, we considered whether the expression profile of in vitro regulated miRNAs (161 probes) could discriminate between ER- positive and ER-negative breast tumours. However, both $t$ test and SAM analysis failed to evidence any correlation. On the contrary, unsupervised hierarchical 
Table 1 ER $\alpha$-binding sites within $10 \mathrm{~kb}$ from loci encoding E2-regulated miRNAs

\begin{tabular}{|c|c|c|c|c|}
\hline miRNA gene & Closest ER $\alpha$ binding site ${ }^{a, b}$ & Closest ER $\alpha$ binding site ${ }^{a, b}$ & Closest ER $\alpha$ binding site ${ }^{\mathrm{a}, \mathrm{c}}$ & Closest ER $\alpha$ binding site ${ }^{\mathrm{a}, \mathrm{c}}$ \\
\hline hsa-miR-135a-2 & - & $4773(\operatorname{chr} 12: 96486593-7225)$ & -7265 (chr12:96474451-56) & $8546(\operatorname{chr} 12: 96490366-0460)$ \\
\hline hsa-miR-181c & - & - & $-3445(\operatorname{chr} 19: 13842950-3068)$ & $5623(\operatorname{chr} 19: 13852245-2362)$ \\
\hline hsa-miR-23a & $-6791(\operatorname{chr} 19: 13815263-6060)$ & $191(\operatorname{chr} 19: 13807531-8210)$ & $-7212(\operatorname{chr} 19: 13815685-99)$ & $786(\operatorname{chr} 19: 13807588-7661)$ \\
\hline hsa-miR-27a & $-6933(\operatorname{chr} 19: 13815263-6060)$ & $44(\operatorname{chr} 19: 13807531-8210)$ & $-7354(\operatorname{chr} 19: 13815685-99)$ & $639(\operatorname{chr} 19: 13807588-7661)$ \\
\hline hsa-miR-24-2 & $\begin{array}{l}0 \text { (overlapping) (chr19: } \\
13807531-8210)\end{array}$ & $\begin{array}{l}0 \text { (overlapping) (chr19: } \\
\text { 13807531-8210) }\end{array}$ & -7649 (chr19:13815685-99) & $486(\operatorname{chr} 19: 13807588-7661)$ \\
\hline hsa-miR-26b & - & $2814(\mathrm{chr} 2: 218978503-9023)$ & - & - \\
\hline
\end{tabular}

${ }^{\text {a }}$ Distance in bps

${ }^{\mathrm{b}}$ ChIP-Seq data from Cicatiello et al. [48]

${ }^{\mathrm{c}}$ ChIP-Seq data from Fullwood et al. [61]

clustering of these probes gave two well-separated branches (Fig. 4a) that correlated with disease-free survival (disease-free or relapsing; DFS) when all the patients were considered $(P<0.05$ in the case of DFS; Fig. 4b), while marginal significance was observed for overall survival (surviving and not surviving; OS). Limiting the analysis to the group of patients receiving Tamoxifen treatment did not increase separation of survival curves, whereas DFS retained marginal significance, this was lost for OS (Fig. 4c). A second kind of analysis was performed to see whether in vitro regulated probes were present among those differentially expressed in defined groups of samples. Again, SAM analysis failed to evidence differentially expressed probes in ER-positive versus ER-negative samples. On the contrary, groups defined by the DFS status and by the OS status were well differentiated. For DFS, we chose 47 probes differentially expressed (median false significant genes $=7.84$ ): of these, five were regulated in vitro in at least one cell line (hsa-miR-122, -194*, $-1238,-1305$ and HS_94). For OS, 63 probes were selected (median FSG06.3): Of these, nine were regulated in at least one cell line (hsa-miR-122, -194*, -646, $-940,1206,1238,-1305$, HS_94 and HS_275). MiRNAs belonging to these groups are shown in Supplementary Table S4.

\section{Discussion}

MicroRNAs represent a class of small non-coding RNAs that control gene expression by targeting mRNAs and thereby triggering either translation repression or RNA degradation. Among human diseases, it has been shown that miRNAs are aberrantly expressed or mutated in cancer, suggesting that they may play a crucial role as a class of oncogenes or tumour suppressor genes. Multiple lines of evidence show the involvement of specific miRNAs in the pathogenesis of $\mathrm{BC}$, where they may represent an alternative molecular mechanism that could impact the onset, development and progression of this hormone-responsive disease. In this study, we investigated the role of oestrogen and its nuclear receptor $\mathrm{ER} \alpha$ in modulating miRNA expression in human BC cells. Once chosen robust and validated cellular models for our study, we performed a time-course profiling analysis to identify miRNAs whose levels are affected by E2 in both MCF-7 and ZR-75.1 cells. This led to the identification, among the 1,145 probes on the miRNA microarray used, of 172 E2-regulated miRNAs (15\% of total). Of these small RNAs, 52 resulted commonly regulated in both cell lines, 51 were regulated only in MCF-7 and 69 regulated only in ZR-75.1 cells. These three sets, characterised by a defined kinetic of response to E2, cluster in two concordant groups of significantly down- or up-regulated miRNAs.

Table 2 E2-regulated miRNAs in MCF-7 and ZR-75.1 cell lines located in the intragenic region of hormone-regulated genes

\begin{tabular}{llll}
\hline miRNA gene & E2 effect on miRNA & Host gene $^{\mathrm{a}}$ & E2 effect on host gene \\
\hline hsa-miR-25 (chr7:99.529.199-202) & Up & MCM7 (chr7:99.528.340-99.537.363) & Up \\
hsa-miR-26a (chr12:56.504.649-742) & Down & CTDSP2 (chr12:56.499.977-56.527.014) & Down \\
hsa-miR-424 (chrX:133.508.310-407) & Up & MGC16121 (chrX:133.505.073-133.508.326) & Up \\
hsa-miR-618 (chr12:79.853.646-743) & Down & LIN7A (chr12:79.715.302-79.855.825) & Down \\
hsa-miR-760 (chr1:94.084.976-5055) & Up & BCAR3 (chr1:937.999.37-940.852.94) & Down \\
hsa-miR-942 (chr1:117.438.788-873) & Up & TTF2 (chr1:117.404.472-117.447.014) & Up \\
\hline
\end{tabular}

${ }^{a}$ Oestrogen-dependent gene regulation data from Cicatiello et al. [48] 
Interestingly, our microarray data reveal that the miRNA 'star' strand, until recently considered the carrier strand devoid of biological significance but now know to be fully functioning and independently controlled by the Ago 2, is most often regulated respect to the corresponding 'non-star' counterpart, which often do not show significant changes when compared to the control (0h-EtOH). The abundance of star sequences in our datasets could be explained by RISC incorporation of star arms, due to the thermodynamic stability of the miRNA-miRNA* duplex. These alternate mature forms share similar evolutionary and structural signatures, and show similar relationships with target 3' UTRs. The results obtained here are also in agreement with the involvement of oestrogen and its receptors in miRNA maturation kinetics, as recently demonstrated for ER $\beta$ in $\mathrm{BC}$ cells by Paris et al. [30]. As these alternate miRNA species target different transcripts respect to non-star strands, they increase the number of targets for each miRNA gene and may constitute also a powerful evolutionary mechanism for the emergence of new miRNAs.

Considering the biological significance of the results obtained, we focused our attention on E2-regulated miRNAs in common between the two $\mathrm{BC}$ cell lines analysed as they represent a good starting point to investigate the role of miRNAs in modulating the final responses to oestrogen of hormone-responsive genes in $\mathrm{BC}$ cells and to understand in depth the spectrum of molecular mechanisms dependent upon oestrogen in BC. Among the many observations made, we noted that, together with miRNAs transcribed as independent transcripts, several miRNA gene clusters show the same changes in response to E2 in both cell lines, suggesting a global effect of ligand-activated receptor on the entire gene locus. Moreover, we observed that most regulated miRNAs exhibit a significant variation in expression 24-72 h after E2 stimulation. This may be due to the fact that increase/decrease of pri- and pre-miR expression level occurs early after E2 stimulation, while mature miRNA expression level start to vary later, as shown by Castellano et al. [58], who focused their attention on the cluster 17-92 and demonstrated that if the pri-miR levels are quickly increased during the first $3 \mathrm{~h}$ of oestrogen stimulation, while the mature forms result mainly increased only after $24-72 \mathrm{~h}$ of oestrogen treatment.

As partial confirmation of the results described here, we observed that a number of miRNAs found oestrogenresponsive in our expression profiling assays were identified also in other studies performed in BC cells. E2, for example, was found to increase expression of some members of the miR-17-92 cluster, as well as of miR-424*, miR-450b-3p/5p and miR-542-3p and of miR-25* [28, 59]. Conversely, it was shown to decrease expression of miR-34a*, let-7e*, miR-125a-3p, miR-181a*, miR-181c*, miR-26b*, miR618 and star members of the miR-23a/27a/24-2 cluster $[28,60]$.
Fig. 4 Analysis of miRNA expression in 30 breast cancer samples. a Hierarchical clustering of 161 miRNAs oestrogen-regulated in vitro in at least one cell line. The blue bars denote ER+ samples. Numbers at the top indicate individual tumour number (see Supplemental Table S3 for details). The two main branches were used in survival analysis: $\mathbf{b}$ Kaplan-Meier survival analysis and log rank test concerning all 30 samples $(p<0.05$ for DFS, top; $p<0.08$ for OS, bottom) or $\mathbf{c}$ limited to patients receiving adjuvant Tamoxifen $(p<0.09$ for DFS, top; NS for OS, bottom). 'N' on the curves denotes the censored events in each group. The miRNAs marked in red are in common between the miRNAs classifying breast tumours and those E2-regulated in BC cell lines

Since miRNAs exert their actions on target mRNAs at the post-transcriptional level, a variation of their cellular levels upon E2 stimulation could have important functional roles. As a consequence, identification of miRNA targets is crucial to understand the functional significance of oestrogenmediated miRNA expression changes in BC cells. For this reason, we performed an in silico target analysis on E2regulated miRNAs and found how almost 33\% of E2responsive mRNAs represent putative targets of regulated miRNAs. To identify inverse relationships between changes in oestrogen-responsive miRNA levels and those of the corresponding target mRNAs, we took in account all mRNAs targeted by a single miRNA. Results reveal 125 mRNAs that show and correlation respect to the matched miRNA (Supplementary Table S1), with a significant prevalence $(p<0.003)$ for down-regulated mRNAs $(14 \%$, ranging from $6 \%$ to $23 \%$ for each of the E2-responsive gene clusters described in these same cell lines [48]), respect to up-regulated ones $(8 \%$, ranging between $3 \%$ and $13 \%$ in the activated gene clusters). These results indicate a deep impact of $\mathrm{E} 2 / \mathrm{ER} \alpha$ on $\mathrm{BC}$ cell transcriptome regulation via $\mathrm{E} 2-$ responsive miRNAs. Considering the biological significance of this finding, we searched biological functions reflecting the activity of mRNAs that are significantly over-represented among all predicted target transcripts by Gene Ontology analysis. The results reported in Supplementary Fig. S2 show that several biological processes are indeed controlled via the miRNA-dependent pathway described here. Indeed, the presence of target genes involved in the cell proliferation, gene transcription, signal transduction and apoptosis indicates that $\mathrm{ER} \alpha$ affects in this way a number of key cellular processes through this posttranscriptional regulatory mechanism where ERs appear to influence the activity of target genes through miRNAmediated post-transcriptional regulation of the activity of gene networks.

Concerning the mechanism for miRNA regulation by the oestrogen receptor, starting from expression profiling and ER $\alpha$ ChIP-Seq and ChIA-Pet data, we propose at least two different mechanisms for hormone-mediated regulation of miRNA gene activity. One is represented by ER $\alpha$ binding in proximity of miRNA-encoding genes that suggests a direct 
a a $\quad 117231385321029618201426152224421321931251230927128$

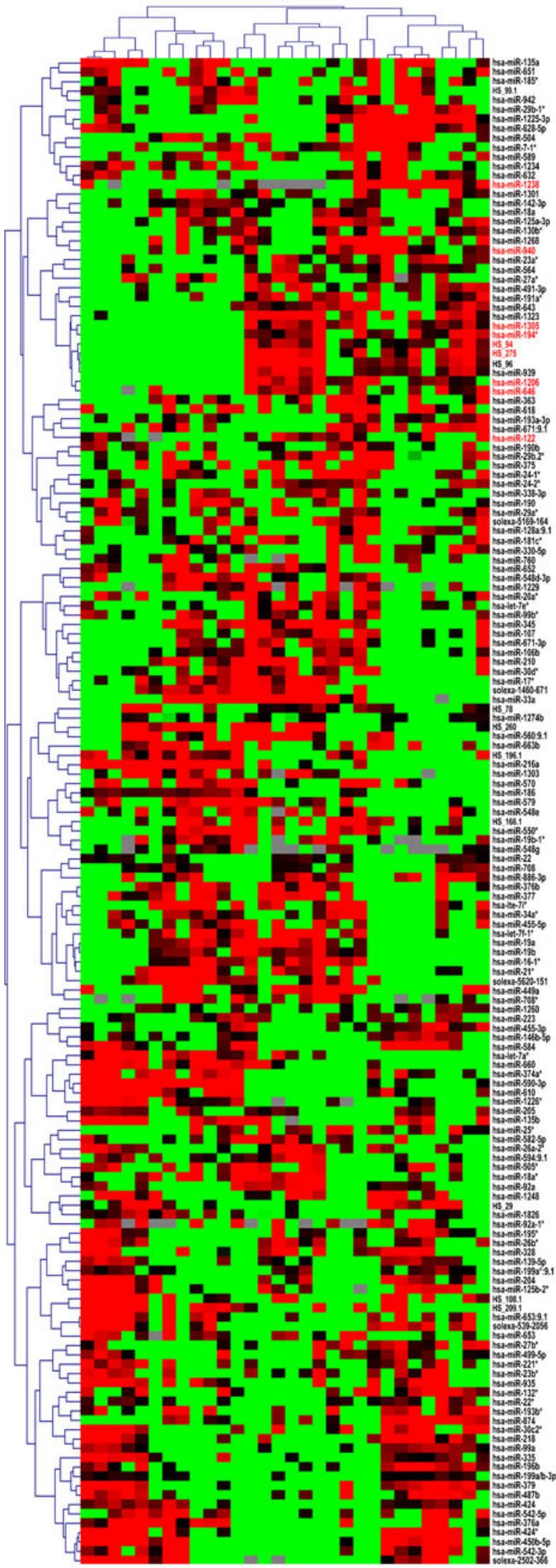

0.0 b
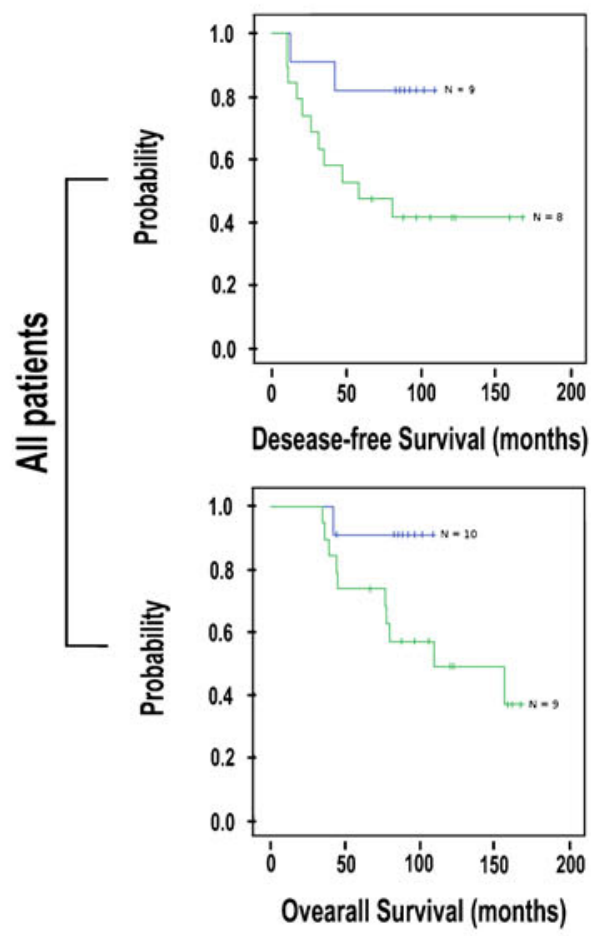

c
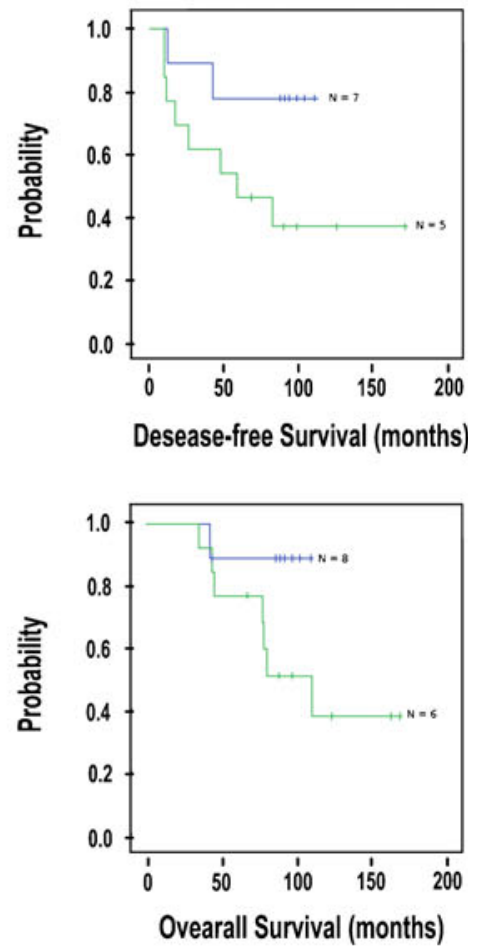
involvement of the receptor in transcriptional regulation of pri-miR synthesis by transcription. As shown in Tables 1 and S2, six E2-regulated miRNAs have an ER $\alpha$ binding site within $10 \mathrm{~kb}$ from the miRNA gene at a major distance $(50 \mathrm{~kb})$, but still compatible with the mechanism cited above. The presence of binding sites for the receptor upstream and/or downstream of E2-downregulated miR-27a, one of the components of the miR-23a-27a/24-2 cluster, is particularly interesting as targets of this miRNA identified based upon changes in protein levels after treatment with a $27 \mathrm{a}$ antagomiR include the transcriptional co-factor ZBTB10/RINZF. ZBTB10 is a repressor of the SP1 transcription factor, which is found overexpressed in a variety of cancers and is thought to play a role in the G0-G1 to S phase progression in BC cells [63]. Similarly, direct upregulation of miR-135a of is interest, considering that this miRNA has been found to be oncogenic, able to regulate APC and Jak2 gene transcripts, which both encode proteins involved in cell survival and proliferation, angiogenesis and immune evasion $[64,65]$. The second E2-mediated miRNA regulation mechanism suggested by the results reported here is represented by the involvement of E2-inducibile expression of mRNA-encoding genes that harbour microRNA genes in their intronic regions. In order to investigate this mechanism, we controlled first which E2-regulated miRNAs were located in host mRNA genes and, subsequently, which of these genes were E2-regulated. In this way, we identified 6 E2-regulated miRNAs that are encoded by a host gene that, in all but one case, is itself regulated by the hormone with the same kinetics (Table 2). These considerations do not exclude, of course, other potential mechanisms by which ligand-activated ER $\alpha$ might affect miRNA expression levels. For example, several studies have demonstrated the presence of a crosstalk of the miRNA maturation pathways with intracellular signaling molecules as p53 [66], Smad proteins [67] and ER itself. Recent findings, in fact, suggest a role for $\mathrm{E} 2 / \mathrm{ER} \alpha$ action in the biogenesis of miRNAs, where ER $\alpha$ is able to down-regulate miRNA expression blocking Drosha-mediated processing of a subset of miRNAs by binding to Drosha in a p68/p72-dependent manner and inducing the dissociation of the microprocessor complex from pri-miRNA [68].

Analysis of miRNA expression in clinical samples confirmed the general finding that these noncoding RNAs show significant associations with clinical outcome more than protein coding genes $[69,70]$. In fact, significant survival curve separations were observed in terms of both diseasefree and overall survival, despite the fact that the cohort of patients examined here is small $(N=30)$. Notably, the group of miRNAs regulated by oestrogen in vitro was found comparably effective in discriminating survival, although the small number of samples does not allow to evidence specific effects in the group of ER-positive, Tamoxifen- treated samples. In contrast, we could not find any association of regulated miRNAs with ER status. One likely explanation for this is that miRNA expression levels in tumours respond to many different stimuli aside from oestrogen receptor-mediated regulation. The same finding was in part true for protein coding RNAs [71]. For the reason stated above, we are not surprised by the fact that there is no direct correlation between hormone-regulated miRNAs and the miRNA profile that correlates with clinical follow-up. Indeed, the number of RNAs found is not significant, as any other set of corresponding size will contain similar numbers of responsive probes.

Overall, our data indicate that miRNA expression play a key role in oestrogen-dependent functions in $\mathrm{BC}$ and possibly other cell types, suggesting that miRNA modulation by $E R \alpha$ represents a novel genetic pathway controlled by these steroid hormones that could impact oestrogen-dependent breast tumour biology and, thereby, influence the clinical and pharmacological profile of the disease.

Acknowledgements The authors thank Rosario Casale and Maria Francesca Papa for technical assistance and Claudio Scafoglio for critically reading the revised manuscript. Work supported by: European Union (CRESCENDO I.P., contract number LSHM-CT2005-018652), Italian Association for Cancer Research (grant IG-8586), Ministry for Education, University and Research (grants PRIN 2008CJ4SYW 004) and University of Salerno (Fondi FARB 2011). CC, FR, GN and RT are fellows of Fondazione con il Sud, MR is supported by a 'Vladimir Ashkenazy' fellowship of Italian Association for Cancer Research, MRDF is PhD student of the Research Doctorate 'Computational Biology and Bioinformatics' of the University of Napoli 'Federico II' supported by Fondazione IRCCS SDN, FC is PhD student of the Research Doctorate 'Molecular Pathology and Physiopathology' of the University of Napoli 'Federico II', GG and SS are PhD students of the Research Doctorate 'Experimental Physiopathology and Neurosciences' of the Second University of Napoli and CS is PhD student of the Research Doctorate 'Molecular Oncology, Experimental Immunology and Innovative Therapy Development' of the 'Magna Graecia' University of Catanzaro.

Conflict of interest The authors declare that they have no conflict of interest.

\section{References}

1. Heldring N, Pike A, Andersson S, Matthews J, Cheng G, Hartman $J$, Tujague $M$ et al (2007) Estrogen receptors: how do they signal and what are their targets. Physiol Rev 87:905-931

2. Hall JM, Couse JF, Korach KS (2001) The multifaceted mechanisms of estradiol and estrogen receptor signaling. J Biol Chem 276:36869-36872

3. Bai Z, Gust R (2009) Breast cancer, estrogen receptor and ligands. Arch Pharm (Weinheim) 342:133-149

4. Kushner PJ, Agard DA, Greene GL, Scanlan TS, Shiau AK, Uht RM, Webb P (2000) Estrogen receptor pathways to AP-1. J Steroid Biochem Mol Biol 74:311-317

5. Saville B, Wormke M, Wang F, Nguyen T, Enmark E, Kuiper G, Gustafsson JA et al (2000) Ligand-, cell-, estrogen receptor 
subtype (alpha/beta)-dependent activation at GC-rich (Sp1) promoter elements. J Biol Chem 275:5379-5387

6. McDonnell DP, Norris JD (2002) Connections and regulation of the human estrogen receptor. Science 296:1642-1644

7. Klinge CM, Jernigan SC, Mattingly KA, Risinger KE, Zhang J (2004) Estrogen response element-dependent regulation of transcriptional activation of estrogen receptors alpha and beta by coactivators and corepressors. J Mol Endocrinol 33:387-410

8. Chen GG, Zeng Q, Tse GM (2008) Estrogen and its receptors in cancer. Med Res Rev 28:954-974

9. Manavathi B, Kumar R (2006) Steering estrogen signals from the plasma membrane to the nucleus: two sides of the coin. J Cell Physiol 207:594-604

10. Safe S, Kim KJ (2008) Non-classical genomic estrogen receptor (ER)/specificity protein and ER/activating protein-1 signaling pathways. J Mol Endocrinol 41:263-275

11. Gronemeyer H, Gustafsson JA, Laudet V (2004) Principles for modulation of the nuclear receptor superfamily. Nat Rev Drug Discov 3:950-964

12. Kim VN (2005) MicroRNA biogenesis: coordinated cropping and dicing. Nat Rev Mol Cell Biol 6:376-385

13. Xiong H, Qian J, He T, Li F (2009) Indipendent transcription of miR-281 in the intron of ODA in Drosophila melanogaster. Biochem Biophys Res Commun 378:883-889

14. Rodriguez A, Griffiths-Jones S, Ashurst JL, Bradley A (2004) Identification of mammalian microRNA host genes and transcription units. Genome Res 14:1902-1910

15. Saini HK, Griffiths-Jones S, Enright AJ (2007) Genomic analysis of human microRNA transcripts. Proc Natl Acad Sci USA 104:17719-17724

16. Lee Y, Kim M, Han JJ, Yeom KH, Lee S, Baek SH, Kim VN (2004) MicroRNA genes are transcribed by RNA polymerase II. EMBO J 23:4051-4060

17. Denli AM, Tops BB, Plasterk RH, Ketting RF, Hannon GJ (2004) Processing of primary microRNAs by the Microprocessor complex. Nature 432:231-235

18. Lee Y, Jeon K, Lee JT, Kim S, Kim VN (2002) microRNA maturation: stepwise processing and subcellular localization. EMBO J 21:4663-4670

19. Gregory RI, Chendrimada TP, Cooch N, Shiekhattar R (2005) Human RISC couples microRNA biogenesis and posttranscriptional gene silencing. Cell 123:631-640

20. Engels BM, Hutvagner G (2006) Principles and effects of microRNA-mediated post-transcriptional gene regulation. Oncogene 25:6163-6169

21. He L, Hannon GJ (2004) MicroRNAs: small RNAs with a big role in gene regulation. Nat Rev Genet 5:522-531

22. Linsen S, Tops B, Cuppen E (2008) miRNAs small changes, widespread effects. Cell Res 18:1157-1159

23. Lewis BP, Burge CB, Bartel DP (2005) Conserved seed pairing, often flanked by adenosines, indicates that thousands of human genes are microRNA targets. Cell 120:15-20

24. Zhao Y, Srivastava D (2007) A developmental view of microRNA function. Trends Biochem Sci 32:189-197

25. Ventura A, Jacks T (2009) MicroRNAs and cancer: short RNAs go a long way. Cell 136:586-591

26. Tessel MA, Krett NL, Rosen ST (2010) Steroid receptor and microRNA regulation in cancer. Curr Opin Oncol 22:592-597

27. Klinge CM (2009) Estrogen regulation of miRNA expression. Curr Genomics 10:169-183

28. Bhat-Nakshatri P, Wang G, Collins NR, Thomson MJ, Geistlinger TR, Carroll JS, Brown M et al (2009) Estradiol-regulated microRNAs control estradiol response in breast cancer cells. Nucleic Acids Res 37:4850-4861

29. Yang Z, Wang L (2011) Regulation of microRNA expression and function by nuclear receptor signaling. Cell Biosci 1:31
30. Paris O, Ferraro L, Grober OMV, Ravo M, De Filippo MR, Giurato G, Nassa G, Tarallo et al. (2012) Direct regulation of microRNA biogenesis and expression by estrogen receptor beta in hormoneresponsive breast cancer. Oncogene. doi:10.1038/onc.2011.583

31. Esquela-Kerscher A, Slack FJ (2006) Oncomirs-microRNAs with a role in cancer. Nat Rev Cancer 6:259-269

32. Iorio MV, Ferracin M, Liu CG, Veronese A, Spizzo R, Sabbioni S, Magri E et al (2005) MicroRNA gene expression deregulation in human breast cancer. Cancer Res 65:7065-7070

33. Lu J, Getz G, Miska EA, Alvarez-Saavedra E, Lamb J, Peck D, Sweet-Cordero A et al (2005) MicroRNA expression profiles classify human cancers. Nature 435:834-838

34. Blenkiron C, Goldstein LD, Thorne NP, Spiteri I, Chin SF, Dunning MJ, Barbosa-Morais NL et al (2007) MicroRNA expression profiling of human breast cancer identifies new markers of tumor subtype. Genome Biol 8:R214

35. Gaur A, Jewell DA, Liang Y, Ridzon D, Moore JH, Chen C, Ambros VR et al (2007) Characterization of microRNA expression levels and their biological correlates in human cancer cell lines. Cancer Res 67:2456-2468

36. O’Day E, Lal A (2010) MicroRNAs and their target gene networks in breast cancer. Breast Cancer Res 12:201

37. Adams BD, Furneaux H, White BA (2007) The micro-ribonucleic acid (miRNA) miR-206 targets the human estrogen receptor alpha (ERalpha) and represses ERalpha messenger RNA and protein expression in breast cancer cell lines. Mol Endocrinol 21:1132-1147

38. Hossain A, Kuo MT, Saunders GF (2006) Mir-17-5p regulates breast cancer cell proliferation by inhibiting translation of AIB1 mRNA. Mol Cell Biol 26:8191-8201

39. Yu Z, Wang C, Wang M, Li Z, Casimiro MC, Liu M, Wu K et al (2008) A cyclin D1/microRNA 17/20 regulatory feedback loop in control of breast cancer cell proliferation. J Cell Biol 182:509-517

40. Gaur A, Jewell DA, Liang Y, Ridzon D, Moore JH, Chen C, Ambros VR et al (2007) Characterization of microRNA expression levels and their biological correlates in human cancer cell lines. Cancer Res 67:2456-2468

41. Volinia S, Calin GA, Liu CG, Ambs S, Cimmino A, Petrocca F, Visone R et al (2006) A microRNA expression signature of human solid tumors defines cancer gene targets. Proc Natl Acad Sci USA 103:2257-2261

42. Gusev Y, Schmittgen TD, Lerner M, Postier R, Brackett D (2007) Computational analysis of biological functions and pathways collectively targeted by co-expressed microRNAs in cancer. BMC Bioinforma 8(Suppl 7):S16

43. Cochrane DR, Cittelly DM, Howe EN, Spoelstra NS, McKinsey EL, LaPara K, Elias A et al (2010) MicroRNAs link estrogen receptor alpha status and dicer levels in breast cancer. Horm Cancer 1:306-319

44. Ambrosino C, Tarallo R, Bamundo A, Cuomo D, Franci G, Nassa $\mathrm{G}$, Paris $\mathrm{O}$ et al (2010) Identification of a hormone-regulated dynamic nuclear actin network associated with estrogen receptor alpha in human breast cancer cell nuclei. Mol Cell Proteomics 9:1352-1367

45. Cimino D, Fuso L, Sfiligoi C, Biglia N, Ponzone R, Maggiorotto F, Russo G et al (2008) Identification of new genes associated with breast cancer progression by gene expression analysis of predefined set of neoplastic tissues. Int J Cancer 123:1327-1338

46. Scafoglio C, Ambrosino C, Cicatiello L, Altucci L, Ardovino M, Bontempo P, Medici N et al (2006) Comparative gene expression profiling reveals partially overlapping but distinct genomic actions of different antiestrogens in human breast cancer cells. J Cell Biochem 98:1163-1184

47. Cicatiello L, Scafoglio C, Altucci L, Cancemi M, Natoli G, Facchiano A, Iazzetti $G$ et al (2004) A genomic view of estrogen actions in human breast cancer cells by expression profiling of the hormone-responsive transcriptome. J Mol Endocrinol 32:719-775 
48. Cicatiello L, Mutarelli M, Grober OMV, Paris O, Ferraro L, Ravo $\mathrm{M}$, Tarallo R et al (2010) A gene network controlled by estrogen receptor $\alpha$ in luminal-like breast cancer cells comprising multiple transcription factors and microRNAs. Am J Pathol 176:2113-2130

49. Ravo M, Mutarelli M, Ferraro L, Grober OMV, Paris O, Tarallo R, Vigilante A et al (2008) Quantitative expression profilino of highly degraded RNA from formalin-fixed, paraffin-embedded breast tumor biopsies by oligonucleotide microarrays. Lab Inv 88:430-440

50. Tusher VG, Tibshirani R, Chu G (2001) Significance analysis of microarrays applied to the ionizing radiation response. Proc Natl Acad Sci 98:5116-5121

51. Grober OMV, Mutarelli M, Giurato G, Ravo M, Cicatiello L, De Filippo MR, Ferraro L et al (2011) Global analysis of estrogen receptor beta binding to breast cancer cell genome reveals an extensive interplay with estrogen receptor alpha for target gene regulation. BMC Genomics 12:36

52. Fejes AP, Robertson G, Bilenky M, Varhol R, Bainbridge M, Jones SJ (2008) FindPeaks 3.1: a tool for identifying areas of enrichment from massively parallel short-read sequencing technology. Bioinformatics 24:1729-1730

53. Qiunian AR, Hall IN (2010) BEDTools: a flexible suite of utilities for comparing genomic features. Bioinformatics 26:841-842

54. Dennis G Jr, Sherman BT, Hosack DA, Yang J, Gao W, Lane HC, Lempicki RA (2003) DAVID: Database for Annotation, Visualization, and Integrated Discovery. Genome Biol 4:P3

55. da Huang W, Sherman BT, Lempicki RA (2009) Systematic and integrative analysis of large gene lists using DAVID Bioinformatics Resources. Nature Protoc 4:44-57

56. Weigelt K, Moehle C, Stempfl T, Weber B, Langmann T (2008) An integrated workflow for analysis of ChIP-chip data. Biotechniques 45:131-132

57. Cicatiello L, Scafoglio C, Altucci L, Cancemi M, Natoli G, Facchiano A, Iazzetti G et al (2004) A genomic view of estrogen actions in human breast cancer cells by expression profiling of the hormone-responsive transcriptome. J Mol Endocrinol 32:719-775

58. Cicatiello L, Addeo R, Altucci L, Belsito Petrizzi V, Boccia V, Cancemi M, Germano D et al (2000) The antiestrogen ICI 182,780 inhibits proliferation of human breast cancer cells by interfering with multiple, sequential estrogen-regulated processes required for cell cycle completion. Mol Cell Endocrinol 165:199-209

59. Castellano L, Giamas G, Jacob J, Coombes RC, Lucchesi W, Thiruchelvam P, Barton G et al (2009) The estrogen receptor- alpha-induced microRNA signature regulates itself and its transcriptional response. Proc Natl Acad Sci U S A 106:15732-15737

60. Maillot G, Lacroix-Triki M, Pierredon S, Gratadou L, Schmidt S, Bénès V, Roché H et al (2009) Widespread estrogen-dependent repression of micrornas involved in breast tumor cell growth. Cancer Res 69:8332-8340

61. Fullwood MJ, Liu MH, Pan YF, Liu J, Xu H, Mohamed YB, Orlov YL et al (2009) An oestrogen-receptor-alpha bound human chromatin interactome. Nature 462:58-64

62. Kim VN, Han J, Siomi MC (2009) Biogenesis of small RNAs in animals. Nat Rev Mol Cell Biol 10:126-139

63. Li X, Mertens-Talcott SU, Shu Z, KyoungHyun K, Judith B, Stephen S (2010) MicroRNA-27a indirectly regulates estrogen receptor alpha expression and hormone responsiveness in MCF-7 breast cancer cells. Endocrinology 151:2462-2473

64. Nagel R, le Sage C, Diosdado B, van der Waal M, Oude Vrielink JA, Bolijn A, Meijer GA et al (2008) Regulation of the adenomatous polyposis coli gene by the miR-135 family in colorectal cancer. Cancer Res 68:5795-5802

65. Navarro A, Diaz T, Martinez A, Gaya A, Pons A, Gel B, Codony C et al (2009) Regulation of JAK2 by miR-135a: prognostic impact in classic Hodgkin lymphoma. Blood 114:2945-2951

66. Suzuki HI, Yamagata K, Sugimoto K, Iwamoto T, Kato S, Miyazono K (2009) Modulation of microRNA processing by $\mathrm{p} 53$. Nature 460:529-533

67. Davis BN, Hilyard AC, Lagna G, Hata A (2008) SMAD proteins control DROSHA-mediated microRNA maturation. Nature 454:56-61

68. Yamagata K, Fujiyama S, Ito S, Ueda T, Murata T, Naitou M, Takeyama K et al (2009) Maturation of microRNA is hormonally regulated by a nuclear receptor. Mol Cell 36:340-347

69. Buffa FM, Camps C, Winchester L, Snell CE, Gee HE, Sheldon H, Taylor M et al (2011) microRNA-associated progression pathways and potential therapeutic targets identified by integrated mRNA and microRNA expression profiling in breast cancer. Cancer Res 71:5635-5645

70. Qian B, Katsaros D, Lu L, Preti M, Durando A, Arisio R, Mu L et al (2009) High miR-21 expression in breast cancer associated with poor disease-free survival in early stage disease and highTGFbeta1. Breast Cancer Rea Treat 117:131-140

71. Weisz A, Basile W, Scafoglio C, Altucci L, Bresciani F, Facchiano A, Sismondi P (2004) Molecular identification of ERalphapositive breast cancer cells by the expression profile of an intrinsic set of estrogen regulated genes. J Cell Physiol 200:440-450 